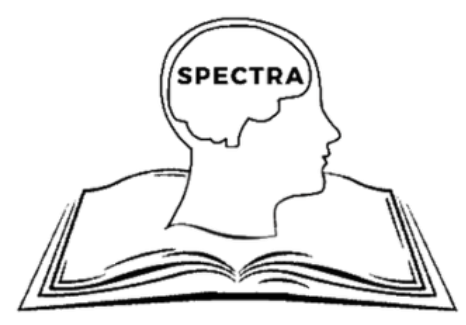

Spectra Undergraduate Research Journal

Volume 1, Issue 1

https://doi.org/10.9741/2766-7227.1001

Office of Undergraduate Research

University of Nevada, Las Vegas

digitalscholarship.unlv.edu/spectra/

\begin{tabular}{|c|}
\hline $\begin{array}{ll} & \text { Category } \\
\end{array}$ \\
\hline Arts, Humanities, and Social Sciences > Liberal Arts > Psychology \\
\hline Received \\
\hline October 19,2020 \\
\hline Accepted \\
\hline January 18,2021 \\
\hline Published \\
\hline February 26, 2021 \\
\hline Article Title \\
\hline Differences in Ethnic and Sport Culture Salience Among College Students Part \\
\hline Authors \\
\hline $\begin{array}{l}\text { Mirella S. Jasso (MSJ) })^{1 *} \text {, Paul Nelson }(\mathrm{PN})^{1} \text {, Bradley Donohue }(\mathrm{BD})^{1} \text {, Michelle Strong }(\mathrm{MS})^{1} \text {, Joanna Kepka }(\mathrm{JK})^{2} \text {, and } \\
\text { Daniel N. Allen (DNA) }{ }^{1}\end{array}$ \\
\hline Author Affiliations \\
\hline $\begin{array}{l}{ }^{1} \text { Department of Psychology, University of Nevada, Las Vegas, Las Vegas, NV, USA. } \\
{ }^{2} \text { Honors College, University of Nevada, Las Vegas, Las Vegas, NV, USA. }\end{array}$ \\
\hline Corresponding Author \\
\hline *Mirella S. Jasso, jassom1@unlv.nevada.edu \\
\hline Author Contributions \\
\hline $\begin{array}{l}\text { MSJ: Contributed to the research with conception, drafting the manuscript, statistical analysis, and interpretation and } \\
\text { implications of the results }\end{array}$ \\
\hline $\begin{array}{l}\text { PN: Contributed to the drafting, revising the manuscript critically, contributed to the theoretical orientations, organization of the } \\
\text { manuscript, statistical analyses, interpretation of the results, and approval of the version to be published }\end{array}$ \\
\hline $\begin{array}{l}\text { BD: Contributed to the research design with conception, research design, planning, revising, and providing final approval of the } \\
\text { version to be published }\end{array}$ \\
\hline MS: Contributed to the conception, planning, data collection, and statistical analysis of this research project \\
\hline $\begin{array}{l}\text { JK: Contributed to the manuscript by revising the manuscript critically for conception and/or grammatical errors and providing } \\
\text { approval for the final defense presentation of this research project from the University of Nevada, Honors College for passing } \\
\text { grade for the Research and Creative Honors Program }\end{array}$ \\
\hline $\begin{array}{l}\text { DNA: Contributed to the conception and planning of the research project, as well as the final approval of the defense presentation } \\
\text { of this research project as a member of the Honor Thesis committee }\end{array}$ \\
\hline Copyright \\
\hline $\begin{array}{l}\text { (c) (7) Articles in Spectra are freely available under a Creative Commons Attribution License (CC BY 4.0) which } \\
\text { allows others to re-use the work without permission as long as the work is properly cited. }\end{array}$ \\
\hline Data Availability Statement \\
\hline The authors of this article confirm that all data underlying the findings are fully available without re \\
\hline $2766-7227$ \\
\hline Conflicts of Interest \\
\hline The authors declare that they have no conflict of interests. \\
\hline Ethical Considerations \\
\hline $\begin{array}{l}\text { This study was approved by the UNLV Institutional Review Board for use of human subjects. No adverse consequences were } \\
\text { expected as a result of participating in the study. }\end{array}$ \\
\hline Funding \\
\hline $\begin{array}{l}\text { This research was made possible by grants to Bradley Donohue (PI) from the National Institute on Drug Abuse (NIDA; } 1 \text { R01 } \\
\text { DA031828), and by scholarships provided to Mirella S. Jasso from the University of Nevada, Las Vegas McNair Scholars } \\
\text { Institute and the Nevada Regents Service Program. }\end{array}$ \\
\hline Recommended Citation \\
\hline $\begin{array}{l}\text { Nelson, P., Donohue, B., Strong, M., Kepka, J., \& Allen, D. N. (2021). Differences in ethnic and sport culture } \\
\text { g college students participating in NCAA and recreational sports. Spectra Undergraduate Research Journal, 1(1), } \\
\text { /doi.org/10.9741/2766-7227.1001 }\end{array}$ \\
\hline
\end{tabular}




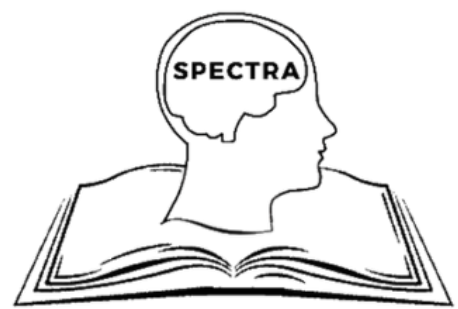

Spectra Undergraduate Research Journal

Volume 1, Issue 1, pp. 16-33

https://doi.org/10.9741/2766-7227.1001

Office of Undergraduate Research

University of Nevada, Las Vegas

digitalscholarship.unlv.edu/spectra/

\section{Differences in Ethnic and Sport Culture Salience Among College Students Participating in NCAA and Recreational Sports}

Mirella S. Jasso ${ }^{1}$, Paul Nelson ${ }^{1}$, Bradley Donohue ${ }^{1}$, Michelle Strong ${ }^{1}$, Joanna Kepka ${ }^{2}$, and Daniel N. Allen ${ }^{1}$

Author Affiliations:

${ }^{1}$ Department of Psychology, University of Nevada, Las Vegas, Las Vegas, NV, USA.

${ }^{2}$ Honors College, University of Nevada, Las Vegas, Las Vegas, NV, USA.

\section{Abstract}

This study aims to (1) examine differences between Ethnic Majority (European American) and Ethnic Minority (African American, Latina/o, Asian/Asian American, Pacific Islander, and Other) student athletes' ratings of importance of their Ethnic Culture, (2) examine differences in the importance of Sport Culture among NCAA and Recreational (i.e., Club and Intramural) student athletes, and (3) determine if Ethnic Identification and Athlete Type interact to predict the importance of Ethnic Culture and Sport Culture. Student athletes were asked to fill out a demographic questionnaire, and then rate the importance of several cultural domains (i.e. Ethnic Culture and Sport Culture) using a novel measure, the Cultural Domain Menu (CDM). After a descriptive analysis was performed, Analysis of Variances (ANOVA) and several t-tests were conducted to test differences among Ethnic Majority and Ethnic Minority student athletes in the importance of their Ethnic and Sport Cultures. Findings demonstrated a significant difference between Ethnic Majority and Ethnic Minority student athletes' ratings of the importance of their Ethnic Culture: Ethnic Majority ratings were found to be lower compared to Ethnic Minority student athletes. Results also showed a significant difference between NCAA and Recreational student athletes in their ratings of their Sport Culture: NCAA student athletes were found to rank their Sport Culture as more salient. Implications, limitations, and future directions for this study are discussed in regard to the results. These results serve as a great indicator of the mental health issues of importance when aiming to serve student athletes from different backgrounds.

Keywords: Cultural salience, Student athletes, Ethnic culture, College students, NCAA, Club sports, Intramural sports, Recreational sports, Sport culture, Identity salience

College student athletes are a special population of interest who must juggle many responsibilities associated with different cultural domains, including academics, religiosity, sexuality, ethnicity, and sports. Difficulties in managing these competing cultural demands have been identified as an important factor in the widespread mental health struggles of student athletes (see Comeaux \& Harrison, 2011). Consequently, the increasing diversity of student athletes has caused a growing interest in research to develop treatments and interventions tailored to consider the student athlete's unique stressors and cultural background (e.g., Martens et al., 2000; Brittian et al., 2013; Jones et al., 2017). Yet there is limited research examining if there is a difference in the importance that student athletes put in their various cultural identities. Knowing that a student athlete puts greater salience in specific cultural domains could help focus future preventative interventions on the relevant context of potential problems. In particular, the 
intersection of Ethnic Culture and Sport Culture might be especially important for student athletes because both Cultures are reasonably the most stigmatized and potentially problematic of Cultures among students. For example, some potential problems students face due to their Ethnic Culture include imposter feelings, racism, and microaggressions (Cokley et al., 2013), whereas some unique stressors student athletes face due to their Sport Culture include the pressure to perform, an elevated risk of depression, and conflict between their athletic duties and their academic responsibilities (Comeaux \& Harrison, 2011; Brewer, 1991; Brewer et al., 1993; Weigand et al, 2013).

Consequently, the present study will examine differences in the salience of Ethnic Culture and Sport Culture in student athletes, what contributes to the salience of these Cultures, and how the personal relevance of these Cultures is associated with each other. Culture in this study will reference a social group of individuals with similarities. For example, Ethnic Culture refers to the behavioral practices and norms of a group of individuals with similar national or cultural origins. Sport Culture refers to the behavioral practices and norms of a group of individuals who engage in sports together. Sport Culture can occur in Recreational team pursuits, such as Intramurals or Clubs, or in more formal and highly competitive team pursuits, such as the National Collegiate Athletic Association (NCAA).

Because the demands, benefits, and risks of participation in highly competitive NCAA sports and Recreational Sports are quite different, it is possible the salience of being an athlete might increase or decrease based on the level of sport participation. Moreover, because NCAA sports expose a person to a much larger social audience with greater consequences (versus Recreational sports), a person's Ethnic Culture might become more or less salient as well. Although extant research has been done on Ethnic Culture and, separately, the role of Sport Culture in student athlete's lives (e.g., Ballesteros \& Tran, 2018; Gurin et al., 2002; Jones et al., 2017; Naoi et al., 2011), an analysis that explores the relationship between these two Cultural Domains in different levels of sport participation has received little attention. Developing an understanding of how Ethnic and Sport Culture are informed by participation in different levels of college sports could be potentially useful in predicting, preventing, and treating student athlete mental health struggles.

\section{Literature Review:}

Sport Culture in NCAA Sports and Recreational Sports

There are a variety of ways that college students can get involved in playing sports, most notably as (1) a highly competitive, institutionally supported, and socially valued NCAA student athlete or as (2) a Recreational student athlete in the form of Intramurals or Club sports. Consequently, Sport Culture in college varies in level of organization, demands, dedication, benefits, risks, and broader cultural significance.

NCAA sports notably differ from Recreational sports by having systematic leadership hierarchies, high competitiveness, national championships, sponsorships, and strong institutional support with financing and personnel from the institutions' athletics department (Lifschutz, 2012). As a result, student athletes participating in NCAA sports appear to dedicate a large amount of time and effort into their Sport Culture (Karoblis, 2016). In a qualitative study done by Paule and Gilson (2010), NCAA athletes reported that one of the drawbacks to this dedication was the feeling of being left out from normal college experiences. Gayles and $\mathrm{Hu}$ (2009) found that student athletes in "high profile" sports (such as football or basketball) were shown to interact less with students who were not their teammates, to have decreased dedication to their academics, and to have less positive cultural attitudes.

Despite the drawbacks that may come from the dedication to NCAA sports, many NCAA student athletes have stated that the benefits outweigh the stress (Paule \& Gilson, 2010). In NCAA sports, student athletes derive value from a sense of accomplishment from competition, reaching personal goals, and improvement in athletic ability (Karoblis, 2016). Many other significant benefits derived from participation in NCAA sports were also reported, including increased time management skills, academic assistance with registration priority and tutors, access to equipment/sports gear, financial scholarships, travel opportunities, life skills in leadership and group dynamics, and the powerful social bonds from being on a team (Paule \& Gilson, 2010). 
In contrast to NCAA sports, Recreational sports tend to be less formal, semester-long sport programs offered by specific universities. Recreational sports give students the chance to increase their physical activity while offering social benefits. For example, Intramural sports offer students the chance to create teams and compete against their classmates in friendly competition, as compared to NCAA sports which offer a more intense competitiveness and longer dedication periods. Cooper et al. (2012) found that students were interested in participating in Intramural sports for the joy of the sport itself, health, fitness, appearance, and social benefits. These findings indicate the salience of Intramural sports to students.

Club sports are another Recreational Sport avenue for student athletes to participate in Sport Culture. Club sports give students who did not qualify in skill or scholarship for NCAA sports to compete with students from other universities. Club sports are, for the most part, run by student leadership and volunteer faculty supervisors. Being run by student leaders allows for greater leadership development among Club sport athletes, yet this also limits the institutional support offered to the sport Club for media representation, financial support, transportation, medical care, and coaches that is offered to NCAA sports (Lifschutz, 2012).

Students who participate in Recreational sports, including Intramural sports and Club sports, tend to devote less time and energy to their sport compared to NCAA athletes. However, Recreational student athletes are still able to derive some of the benefits that NCAA student athletes get from their sport while avoiding many of the stressors that come from the significant demands associated with NCAA participation. In a qualitative study done by Chen, Snyder and Magner (2010), it was agreed among all sport participation levels (NCAA, Club, and Intramural) that the student athlete's Sport Culture was beneficial in developing health, work ethics, creativity, self-esteem, confidence cultural acceptance, academic performance, and overall development.

Unique Stressors and Benefits Associated with Ethnic Minority Student Athletes

The college student athlete population is growing increasingly diverse as more people who identify with Ethnic Minority groups join the sports realm. From 2008 to 2018, the number of African
American Collegiate Athletes increased by over 18,000 athletes, the number of Hispanic Collegiate Athletes increased by over 12,000, and the number of Asian Collegiate Athletes increased by almost 3,000 (National Collegiate Athletic Association, 2018); Ethnic Minorities made up about $35 \%$ of the overall student athlete population as of 2018. As the student athlete population becomes more diverse so do their values and backgrounds. Recognizing this increased diversity in student athletes has incited a growth of research interested in developing treatments and strategies tailored to consider student athletes' unique stressors and cultural backgrounds (i.e., Martens et al., 2000; Ballesteros \& Tran, 2018; Thompson, 2010; Jones et al., 2017; Naoi et al., 2011). However, few interventions have addressed the importance that student athletes' place on their diverse cultural background. Failure to account for the distinct experiences of student athletes can impact our ability to create an inclusive college experience accounting for all students' needs.

Surprisingly, among a student population sample examined, $81 \%$ of African American athletes, $78 \%$ of Latinx American athletes, and $79 \%$ of Asian American athletes expressed some form of a mental health need. Increased reports of feeling overwhelmed and exhausted can stem from the large commitment these student athletes dedicate to their sports alone (i.e., over 20 hours a week), as well as from trying to manage an athletic identity and Ethnic Minority identity (Ballesteros \& Tran, 2018; New, 2015). For example, in a study done by Cokley et al. (2011) among the students examined, Ethnic Minority students demonstrated significantly higher perceived discrimination and significantly lower overall mental health as compared to Ethnic Majority students. Other unique stressors to Ethnic Minority students include Ethnic Minority status stress, racism, and microaggressions (Cokley et al., 2013). These symptoms and stressors may significantly increase if an Ethnic Minority student athlete is attending an Ethnic Majority dominant institution. Indeed, Ethnic Minority student athletes attending predominantly European American institutions face increased psychological distress as well as feelings of isolation, exploitation for their athletic ability, and a lack of support from school administrators (Melendez, 2008; Thompson, 2010). For example, it is not unusual for 
Ethnic Minority students to encounter faculty who believe their admittance into the University was a special circumstance, that is, that the University lowered their standards to allow an Ethnic Minority athlete to be admitted as a student. These highlighted issues can affect Ethnic Minority student athletes' performance as college students as well as diminished mental health and well-being (Cokley et al., 2013).

Although Ethnic Minority students experience many unique challenges, a diverse composition of college student athletes also has numerous benefits. For example, Brittian et al. (2013) found that a diverse Ethnic composition was associated with better adjustment, less feelings of anxiety, and a greater likelihood of affirmation in Ethnic identity for college students. Often, the college campus is a student's first exposure to diversity, forcing them to think critically about their own perceptions, and encouraging mindful thinking (Brittian, et al. 2013). This mindful thinking sparked from being faced with diversity helps encourage cognitive growth and personal development (Gurin et al., 2002). Potuto and O'Hanlon (2007) surveyed 930 student athletes on their college experience and found that most agreed that their experiences with diversity in athletics positively impacted their college experience and helped them gain a better understanding of people from different Ethnic backgrounds. Comeaux (2013) did a long-term study that revealed that cross racial-ethnic interactions among student athletes demonstrated greater levels of leadership orientation. Although these studies do not highlight the importance of Ethnic Culture for student athletes, they demonstrate the benefits students gained from exposure to diverse Ethnic Cultures.

For student athletes, cross Ethnic group engagement may be even more imperative for adjustment into college, and specifically so with their team. As diversity in Ethnic makeup of the student athlete population increases, so do their sports teams. Cross Ethnic-racial interactions have been shown to be significantly important in student athletes' satisfaction with their college, and to increase positive racial attitudes in general (Jones et al., 2017). As well, Brown et al. (2003) argues that due to the deep integration of the athletic identity for student athletes, Ethnic-race differences become less salient on the playing field. This view on the role of Ethnic Culture for the student athletes is important to consider regarding the aims of this study, as it suggests that Ethnic Culture becomes less important, and Sport Culture more important, for student athletes specifically while participating in the sport context. We aim to investigate more in depth the role of Ethnic Culture and Sport Culture in student athletes' lives.

\section{The Present Study}

There is a recent growth in literature regarding the array of cultural issues student athletes are currently facing. Although some research touches on the implications of Ethnic diversity for student athletes (Brown et al, 2003; Jones et al., 2017; Naoi et al., 2011; etc.), there are few publications that specifically measure how important that Ethnic Culture is to student athletes specifically, and that compare differences parsed by Ethnic identity. Although, there are sport psychologists that have addressed the differences between NCAA Sport and Recreational Sport student athletes (Cooper et al., 2012; Paule \& Gilson, 2010; Karoblis, 2016), there are few published studies that quantitatively address the importance of Sport Culture among these Athlete Types (i.e., $\underline{\text { Chen et }}$ al, 2010). In addition, there is a gap in the literature regarding the relationship between the variables of importance in Ethnic Culture and importance of Sport Culture. This study aims to bring a clear answer to the question of how important Ethnic Culture really is to student athletes and how that influences the importance of Sport Culture. The findings of this study may prove useful in understanding how to better aid the unique populations within Sport Culture during their college experience.

Accordingly, the aim of the present study is to determine if self-reported Ethnicity and level of athletic participation are reliably associated with the salience of Sport Culture and Ethnic Culture in college student athletes. We expect that student athletes who identify as an Ethnic Majority group will rate their Ethnic Culture importance significantly lower as compared to student athletes who identify as an Ethnic Minority group. We also expect that NCAA student athletes will rank the importance of Sport Culture significantly higher than Recreational Athlete Types. The literature supports our hypothesis of student athletes participating in NCAA Athlete Type ranking their Sport Culture as more salient than the Recreational Athlete Types (Intramural/Club) because 
the NCAA Athlete spends much more time in their sport, has significantly more sport demands, and is privileged on campus due to the scholarship and the elevated experience these athletes receive (Chen et al., 2010; Karoblis, 2016; Lifschutz, 2012). Similarly, Ethnic Minority student athletes are expected to rate their Ethnic Culture higher than Ethnic Majority student athletes because they are more likely to experience discrimination because of their Ethnicity and their socially valued athleticism is often attributed to their Ethnicity (Melendez, 2008; Thompson, 2010).

\section{Methodology}

Participants: Participants were 62 student athletes from a southwestern university. 38 student athletes reported as NCAA athletes and 24 reported as Recreational athletes (i.e., 22 Intramural athletes and 2 Club athletes). During the time of referral, participants were required to be at least 18 years of age, $\left(M_{\text {Age }}=\right.$ $19.9, S D=1.49$, range $=18-27)$. The student athletes were referred to the study through multiple venues: the athletics department, coaches/teammates, team workshops, study presentations at campus events, and online advertisements as an option to fulfill psychology course research participation requirements. Thirtyeight percent $(n=24)$ of the participants identified as women. Participants reported their Ethnic Identification as European American / White (37\%, $n$ $=23)$, Hispanic/Latina/o $(16 \%, n=10)$, African American (13\%, $n=8)$, Asian/Asian American (9\%, $n$ $=6)$, Pacific Islander $(3 \%, n=2)$, and Other $(21 \%, n=$ 13). Due to the small sample size, Ethnic Identification groups were also dichotomized by an Ethnic Minority group (Hispanic/Latino, Black/African American, Asian/Asian American, Pacific Islander, and Other, $63 \%, n=39$,) and an Ethnic Majority group (European American / White, 37\%, $n=23$ ) in order to conduct statistical analyses. See Table 1 for demographic frequencies.

\section{Measures:}

\section{Demographic Questionnaire}

Demographic information collected included Age, Gender, Ethnicity (European/White, African American/Black, Asian/Asian American, Hispanic/Latino, Pacific Islander, or Other), Current Year in School (Freshman, Sophomore, Junior, or Senior), Athlete Type (NCAA, Intramural, Club, or Non-athlete), Referral Type (athletic department, presentation, coach/teammate, or class credit), marriage status (single or married/cohabiting), financial support (e.g., scholarship or not) and grade point average.

\section{Cultural Domain Menu (CDM)}

The CDM is a novel measure created by one of the authors (Donohue) and his students after brainstorming common cultural identities that are endorsed by college students. Participants were asked to complete the $\mathrm{CDM}$ by rating and ranking the importance of several Cultures from a given menu of options (i.e., Ethnic Culture, Religious/ Spirituality Culture, Gender Identity/Sexuality Culture, Academic Culture, Work/Employment Culture, Greek Culture, and Sport Culture). Rating the importance of Culture was done on a 7 point Likert scale ranging from (1) Extremely Unimportant to (7) Extremely Important.

\section{Procedure}

Participation took place in person at the University of Nevada, Las Vegas. After consenting, participants were presented with the Demographic Questionnaire. Participants then completed the Cultural Domain Menu (CDM) to rate the importance of their Ethnic Culture and to rate the importance in their Sport Culture. After completing the survey, participants were thanked and compensated for their time with Sona credit. This study was approved by the local institutional review board. No adverse consequences were expected as a result of participating in the study.

\section{Results}

Descriptive Analyses: Two between subjects ANOVAs were conducted to compare the differences in age among Ethnic Groups (European American/White, African American, etc.) and Athlete Type (Intramural, Recreational). There was no significant difference between Ethnicity and ages of the student athletes $[F(12,276)=0.81, p=0.639]$. As well, there was no significant difference between Athlete Type and Age of the student athletes [ $F(12$, 276) $=1.29, p=0.225]$.

A Chi Square was conducted to determine whether there was an association between Gender and Athlete Type (Intramural, Recreational). The relation between these variables was not significant, $\left(\mathrm{X}^{2}(2), N\right.$ $=62,=50.99, p>.05)$. These results indicate that for the student athletes examined, there was not a 
significant relationship between Gender and Athlete Type.

Correlations were computed on all 7 Cultures in the CDM to explore the relationship among the domains of this novel measure. Because several correlations were run $(n=21)$, a Bonferroni correction was applied to reduce Type 1 error. The results suggest that 8 out of the 21 relationships were significantly correlated (see Table 2). Of particular interest to the present study, Sport Culture was significantly and negatively correlated with Greek Culture to a large degree $(r=.531)$. Also of special interest to this study, Ethnic Culture was significantly and positively associated with Gender Culture $(r=.52)$ and Religious Culture $(r=.50)$ to a large degree. Last, it is also noteworthy that Work/Employment Culture was significantly and positively correlated with three other Cultures, the most of any cultural domain measured: Academic Culture, Gender/Sexual Identity Culture, and Religious/Spiritual Culture.

\section{Main Analyses}

Ratings of importance in Ethnic Culture: Two independent samples t-tests were conducted to compare ratings of the importance of Ethnic Culture under the conditions of the athletes' Ethnic background (Ethnic Minority or Majority) and their Athlete Type (NCAA or Recreational; see Figure 1 and Figure 2). There was a significant difference in ratings of importance of Ethnic Culture for Ethnic Majority athletes $(M=3.174, S D=1.403)$ and Ethnic Minority athletes $(M=4.821, S D=1.553), t(60)=$ 4.1752, $p=.000$. There was also a significant difference in ratings of importance in Ethnic Culture for NCAA $(M=3.816, S D=1.738)$ and Club/Intramural athletes $(M=4.833, S D=1.434) ; t$ $(60)=-2.397, p=.020$. These results suggest that the Ethnic background student athletes identify with does have an effect on the importance placed in their Ethnic Culture. Specifically, our results suggest that when student athletes identify as an Ethnic Minority (Hispanic/Latino, Black/African American, Pacific Islander, Other) that they are more likely to rate their Ethnic Culture as more important than student athletes that identify with an Ethnic Majority background. Likewise, students in Recreational sports have a greater likelihood to rate their Ethnic Culture as more important than NCAA student athletes.
Ratings of importance in Sport Culture: Two independent t-tests were also conducted to compare ratings of the importance of Sport Culture under the conditions of Athlete Type and Ethnic background (see Figure 3 and Figure 4). There was a significant difference in ratings of importance in Sport Culture for NCAA $(M=6.211, S D=.741)$ and Recreational athletes $(M=5.667, S D=1.204), t(60)=2.206, p=$ .031 . In contrast, there was not a significant difference in ratings of importance of Sport Culture for Ethnic Majority $(M=6.173, S D=.834)$ and Ethnic Minority athletes $(M=5.897, S D=1.046), t(60)=1.080, p=$ .284. These results demonstrate that Athlete Type has a significant effect on ratings of importance in Sport Culture. Student athletes who participate in NCAA sports tend to rate their Sport Culture as more important than Club/Intramural athletes, and that Ethnic background does not have an effect on ratings of importance in Sport Culture for the student athletes examined.

\section{Discussion}

Implications of the Results:

\section{Differences in Salience of Ethnic Culture}

The findings from this study revealed that there are significant differences between Ethnic Minority and Ethnic Majority student athletes in the salience of Ethnic Culture. Specifically, in support of our hypothesis, when student athletes identified as an Ethnic Minority (Hispanic/Latino, Black/African American, Pacific Islander, Other) they are more likely to rate their Ethnic Culture as more important than student athletes that identify with an Ethnic Majority (European/White) background. Understanding what Culture student athletes find most salient based on their Ethnic background and Athlete Type helps us understand what needs may be prioritized and addressed when serving them. For example, if we know that Ethnic Minority student athletes tend to find their Ethnic Culture as the most important among the various Cultures they participate in, we can highlight potential mental health risks they may be facings, such as imposter feelings, Ethnic Minority status stress, racism, and microaggressions (Cokley et al., 2013). Learning how to gain a multicultural understanding of individuals as a clinician or sport psychologist is essential in order to provide the most effective treatment for the issues that are unique to their 
experiences (Martens et al., 2000). By increasing our understanding of student athletes' values and experiences clinicians are able to better serve them. This study also brings to attention the need for student athletes' mental health to be addressed by increasing access to services that are tailored to their needs. As highlighted by the Naoi et al. (2011), Ethnic Minority athletes' value being matched with a consultant of their same Ethnic background or that have experience working with diverse populations, as this influences the consultation relationship.

Our results also supported our hypotheses by demonstrating that students in Recreational sports rated their Ethnic Culture as more important than NCAA student athletes. This finding may indicate that for students engaged in less competitive and less demanding sport participation levels, the salience of their Sport Culture is decreased as compared to students engaged in sports participation levels such as NCAA. This finding aligns well with the research as NCAA athletes Sport Culture has shown to play a large role in their life due to the amount of dedication in effort and time it requires (Karoblis, 2016). Although Recreational sports, such as Club and Intramural sports, can vary in dedication, their structure and competition are not as extensive (Karoblis, 2016; Cooper et al., 2012; Lifschutz, 2012). Therefore, for Recreational student athletes their amount of dedication to their sport may leave more room for other Cultures (i.e., Ethnic Culture) to become more salient.

\section{Differences of Salience in Sport Culture}

According to Yashuko and Davidson's (2009) identity salience model, people are able to adapt the salience of the various aspects of their identities according to the particular contexts they are in. Although Ethnic Minority student athletes and Recreational student athletes were shown to have higher ratings of salience in their Ethnic Culture, that does not indicate an absence of valuing their other Cultures in different contexts, including aspects of their Sport Culture. According to our results, and in support of our hypotheses, student athletes who participated in NCAA sports tended to rate their Sport Culture as more important than Recreational athletes. One reason this finding may have occurred includes the greater degree of dedication and effort NCAA athletics requires as compared to Intramural and Club sports. NCAA athletes often take more than 20 hours a week engaged in their sport (Karbolis, 2016). With a greater prominence in their life due to time dedication and effort, salience in Sport Culture likely increases as well.

Ethnic background did not have an effect on ratings of importance in Sport Culture for the student athletes examined. Although this finding does not support our hypothesis, it is supported by some researchers who believed that differences due to Ethnic background disappear on the playing field (Brown et al., 2003; Chen et al, 2010). Within this view, student athletes' athletic identity becomes the most prominent Culture when placed in organized, highly competitive sports. This suggests that strong involvement in sports could serve as a protective factor against ethnic or racial stigma. This claim should receive focused empirical attention.

\section{Limitations}

Due to our small sample size, we had to dichotomize our Ethnic groups as well as our Athlete Types. With respect to Athlete types, this limited our ability to analyze Intramural and Club athletes separately. This may have had an effect on results as the experiences between Club and Intramural sports may differ in important ways. Although both Intramural and Club sports are not as strenuous and large as NCAA sports, they do have different implications on how they may be salient in the student athletes' lives. For example, in a study done by Karoblis (2016), it was revealed that Club athletes do not receive a scholarship and must put in their own funds to participate in their sport. Putting in their own funds seemed to increase importance in Sport Culture for Club athletes. In contrast, Intramural athletes were found to derive importance in their Sport Culture for the social benefit and physical activity (Cooper et al., 2012). Furthermore, Lifschutz (2012) found that student athletes participating in Club sports were more at risk for hazing accidents during travel and engaged in unhealthy behaviors due to the lack of supervision that is associated with this Athlete Type.

Likewise, dichotomizing Ethnic groups provided an extremely simplistic view of Ethnicity. Combining six Ethnic groups into an Ethnic Minority Group limited our ability to analyze each Ethnic group individually for differences in the salience of their Ethnic Culture and Sport Culture. For example, there 
are arguably more differences in the historical and present day experiences of African Americans and Asian Americans and Latino/a's in the United States than there are similarities, even though there are shared elevated risks to experience ethnic and racial discrimination. Exploring individual differences among specific Ethnic groups could help identify more unique risk factors and barriers that may prevent these student athletes from seeking services based on their particular Ethnic background.

Furthermore, we adopted an Ethnicity lens to frame our findings. We assume that our participants associated Ethnic Culture and their identity as, for example, an African American or Asian American, with a certain set of behavioral practices, a certain status within their larger lived communities, and identification with a unique national origin history. However, some scholars might reasonably argue that some of our measured constructs reflect visible physical features of race, and not Ethnicity. Some other measures of identity and Culture found in the literature note the importance of capturing behaviors, values, knowledge, emotions, and beliefs in a more extensive way. These aspects of identity are important in order to capture a clearer view of students' cultural experiences. Specifically, Martens et al. (2000) offer some recommendations on how to gain a better understanding of the experience of student cultural groups by reading and listening to case examples and obtaining in-field experience. This method would allow for an in-depth understanding of cultural differences and their applications for student athletes. Because our Cultural Domain Menu measure is novel and intentionally simplistic to afford delivery in a clinical intake context, more empirical work must be conducted to better understand how participants are responding to these survey questions and how reliable the measure is over time. Nevertheless, we argue that the short demographic and cultural measures employed in this study are crucial, despite their limitations, to gather important information in the truncated time frame of a clinical assessment of student athletes.

Another limitation of this study is that data was collected at a single time point. If this study were done longitudinally perhaps an investigation into how the salience of identity changes with respect to Sport and Ethnicity Culture as the student athlete reaches the end of their college career would be possible. Indeed, one of the biggest questions in the research of identity development is how self-identity changes throughout the lifespan, and especially during the critical identity period of emerging adulthood (Azmitia et al., 2008). Understanding how self-identity changes overtime in student athletes would be beneficial in order to better learn how to protect this population from potential harmful effects associated with identity struggles, such as dissociation, depression, self-doubt, delayed career development, and increased risk of suicide (Murphy et al., 1996; Brittain et al., 2013).

\section{Future Directions}

This is the first time the Cultural Domain Measure has been used to quickly gather the salience of seven key cultural domains from student athletes. Although our preliminary findings of the connection between some of these domains is intriguing, including the negative correlation between Sport and Greek Culture, or the positive correlations between Ethnic Culture and Religious/Spirituality and Gender Identity/Sexuality Cultures, more focused work is needed to understand the meaning of these associations. Of particular interest, we found that the Work/Employment Cultural domain was significantly and positively correlated with three other cultures, the most of any cultural domain measured: Gender/Sexual Identity Culture, Religious/Spiritual Culture, and Academic Culture. Future research should examine whether Work Culture occupies an especially important integrative force for the identity of college student athletes, and for emerging adults more broadly.

Indeed, future research can use the present study as a model when investigating the salience of identities among student athletes, with the following recommendations. In order to get a clear picture of specific differences among various Ethnic groups and Athlete Types, obtaining a large and evenly distributed sample size is recommended. It would also be helpful if additional in-depth measures of identity and cultural values were utilized to better understand the complex variation in how these cultural domains are practiced, and how they interact (i.e., moderate or mediate) the effects of each other on mental health, academic, performance, or athletic performance. As well, future studies are encouraged to collect more concrete information, such as the actual time and effort spent within each of the cultural domains, within a student 
athlete's life to help determine the relationship between the dedication to an activity and the salience of the cultural domain. Understanding barriers to mental health services, as well as services preferred based on different cultural backgrounds, may also help to serve mental health professionals hoping to address student athletes' mental health struggles.

In order to see how ratings of importance among these Cultures change over time, collecting data over the entire period of a student athlete's college career would give an important view into how identity values develop as a student athlete matures. For example, the demands of both Sport Culture and Ethnic Culture might be especially likely to create conflict over time for Ethnic Minority student athletes' identities, known as identity confusion. Identity confusion in student athletes may result in self-doubt and other psychological problems (Pinkerton et al., 1989). However, some research has posited how group membership has helped individuals cultivate positive identity formation, and that Ethnic identity in particular is an essential element in the psychosocial development for many Ethnic Minorities (Brittian et al., 2013; Phinney \& Ong, 2007). The family involvement and cultural practices of Minority emerging adults have been found to be more salient in comparison to Ethnic Majority emerging adults (Syed \& Mitchell, 2013). Thus, increased salience in Ethnic Culture identity may serve as a protective factor for identity confusion or as a risk factor for identity confusion in Ethnic Minority student athletes. Future research is needed to examine these potential risks and benefits of increased Ethnic Culture in Ethnic Minority student athletes.

Last, some of the concerns and implications brought to the attention among college student athletes in this study may also apply to professional athletes. Student athletes, however, have many different stressors and contexts than professional athletes. For example, most professional athletes do not have academic stress to worry about. As well, professional athletes are in a different, older, developmental stage and therefore may have different life concerns and mental health struggles. Nevertheless, understanding what Cultures professional athletes find most salient may help mental health counselors better serve professional athletes as well. In conclusion, how the salience of different Cultures impacts the mental health and performance of all athletes, whether they are students or professionals, Ethnic Minorities or Ethnic Majorities, is a fruitful field of play for future research.

\section{Acknowledgements}

I would like to thank my faculty mentors Dr. Nelson and Dr. Donohue for their continuing patience and guidance for me throughout the process of creating, presenting, and writing this thesis project. I would also like to thank my thesis committee for their assistance and cooperation in the completion of this thesis. The graduate students Michelle Strong and Karolyne Stucki also deserve acknowledgement for their aid and encouragement. And lastly, I would like to thank my lab mates from The Optimum Performance Program research lab, for their continuous support, confidence, and inspiration.

\section{References}

Azmitia, M., Syed, M., \& Radmacher, K. (2008). On the intersection of personal and social identities: Introduction and evidence from a longitudinal study of emerging adults. New Directions for Child and Adolescent Development, 120, 1-16.

Ballesteros, J. \& Tran, A. G. T. T. (2018). Under the face mask: Racial-ethnic minority studentathletes and mental health use. Journal of American College Health, 66, 1-7.

Brewer, B. W. (1991). Athletic identity as a risk factor for depressive reaction to athletic injury. (Publication No. 9025747). [Doctoral dissertation, Arizona State University]. University Microfilms International.

Brewer, B. W., Van Raalte, J. L., \& Linder, D. E. (1993). Athletic identity: Hercules' muscles or Achilles' heel. International Journal of Sport Psychology, 24(2), 237-254.

Brittian, A. S., Umaña-Taylor, A. J., \& Derlan, C. L. (2013). An examination of biracial college youths' family ethnic socialization, ethnic identity, and adjustment: Do self-identification labels and university context matter? Cultural Diversity and Ethnic Minority Psychology, 19(2), 177-189.

Brown, T. N., Jackson, J. S., Brown, K. T., Seller, R. M., Keiper, S., \& Manuel, W. J. (2003). "There's no race on the playing field" 
Perceptions of racial discrimination among White and Black athletes. Journal of Sport \& Social Issues, 27(2), 162-183.

Chen, S., Snyder, S., \& Magner, M. (2010). The effects of sport participation on studentsathletes' and non-athlete students' social life and identity. Journal of Issues in Intercollegiate Athletics, 3, 176-193.

Cokley, K., Hall-Clark, B., \& Hicks, D. (2011). Ethnic minority-majority status and mental health: The mediating role of perceived discrimination. Journal of Mental Health Counseling, 33(3), 243-263.

Cokley, K., McClain, S., Enciso, A., \& Martinez, M. (2013). An examination of the impact of minority status stress and imposter feelings on the mental health of diverse ethnic minority college students. Journal of Multicultural Counseling and Development, 41, 82-95.

Comeaux, E. (2013). The long-term benefits of crossracial engagement on workforce competencies for Division I White student-athletes. Journal of Student Affairs Research and Practice, 50(1), 37-55.

Comeaux, E. \& Harrison, K. C. (2011). A conceptual model of academic success for studentathletes. Educational Researcher, 40(5), 232245.

Cooper, N., Schuett, P. A., \& Phillips, H. M. (2012). Examining intrinsic motivation in campus intramural sports. Recreational Sports Journal, 36, 25-36.

Gayles, J. G. \& Hu, S. (2009). The influence of student engagement and sport participation on college outcomes among Division I student athletes. The Journal of Higher Education, 80(3), 315-333.

Gurin, P., Dey, E. L., Hurtado, S., \& Gurin, G. (2002). Diversity and higher education: Theory and impact on educational outcomes. Harvard Educational Review, 72(3), 330366.

Jones, W. A., Liu, K., \& Bell, L. F. (2017). The benefits of cross-racial engagement on the college satisfaction of student-athletes. Journal of Student Affairs Research and Practice, 54(4), 371-387.
Karoblis, E. C. (2016). Motivation, athletic identity, and commitment to sport in Division I varsity athletes and collegiate club level athletes: A qualitative analysis (Publication No. 1468) [Doctoral dissertation, Georgia Southern University]. Electronic Theses and Dissertations.

Lifschutz, L. (2012). Club sports: Maximizing positive outcomes and minimizing risks. Recreation Sports Journal, 36, 104112.

Martens, M. P., Mobley, M., \& Zizzi, S. J. (2000) Multicultural training in applied sport psychology. The Sport Psychologist, 14, 8197.

Melendez, M. C. (2008). Black football players on a predominantly White college campus:

Psychosocial and emotional realities of the Black college athlete experience. Journal of Black Psychology, 34(4), 423-451.

Murphy, G. M., Petitpas, A. J., \& Brewer, B. W. (1996). Identity foreclosure, athletic identity, and career maturity in intercollegiate athletes. The Sport Psychologist, 10, 239-246.

Naoi, A., Watson, J., Deaner, H., \& Sato, M. (2011). Multicultural issues in sport psychology and consultation. International Journal of Sport and Exercise Psychology, 9(2), 110-125.

National Collegiate Athletic Association. (2018). NCAA Demographics Database [Data visualization dashboard]. Retrieved from http://www.ncaa.org/about/resources/research /ncaa-demographics-database

New, J. (2015, May 8). College athletes say they devote too much time to sports year-round. https://www.insidehighered.com/news/2015/0 5/08/college-athletes-say-they-devote-toomuch-time-sports-year-round.

Paule, A. L. \& Gilson, T. A. (2010). Current collegiate experiences of big-time, nonrevenue, NCAA athletes. Journal of Intercollegiate Sport, 3, 333-347.

Pennington, B. (2008, December 2). Rise of college club teams creates a whole new level of success. New York Times.

Phinney, J. S. \& Ong, A. D. (2007). Conceptualization and measurement of ethnic identity: Current status and future directions. 
Journal of Counseling Psychology, 54(3), 271281.

Pinkerton, R. S., Hinz, L. D., \& Barrow, J. C. (1989). The college student-athlete: Psychological considerations and interventions. Journal of American College Health, 37(5),218-226.

Potuto, J. R., \& O'Hanlon, J. (2007). National study of student-athletes regarding their experiences as college students. College Student Journal, 41(4), 947-966.

Thompson, J. (2010). Social support and minority student-athletes. Journal of Issues

in Intercollegiate Athletics, 3, 234-252.
Weigand, S., Cohen, J., \& Merenstein, D. (2013). Susceptibility for depression in current and retired student athletes. Sports Health, 5(3), 263-266.

Yashuko, O., Davidson, M. M., \& Williams, E. N. (2009). Identity salience model: A paradigm for integrating multiple identities in clinical practice. Psychotherapy: Theory, Research, Practice, Training, 46(2), 180-192. 
Appendix A: Multiple Regression Results

Due to small sample size limitations, we decided to utilize t-tests for main analyses. However, we present regression findings here in the interest of guiding future data collection. A multiple linear regression was conducted to test the effect of Ethnicity, Athlete Type, and their interaction (Ethnicity X Athlete Type) on Ethnic Culture salience. The regression was found to be significant $[F(3,58)=6.650, p<.001]$ with an $R^{2}$ of .256 . Participants' predicted ratings of the importance in their Ethnic Culture was equal to $3.056+1.444$ (Ethnicity) +0.544 (Athlete Type) + 0.113 (Ethnicity X Athlete Type). Athlete Type was coded as $0=$ NCAA, 1 $=\mathrm{Club} /$ Intramural, and Ethnicity was coded as $0=$ Ethnic Majority, $1=$ Ethnic Minority. Ratings of importance in Ethnic Culture increased by 1.444 for each Ethnic background group and 0.544 for each Athlete Type. Ethnicity was a significant predictor of ratings of importance in Ethnic Culture. Athlete Type and the interaction variable (Ethnicity X Athlete Type) were not significant predictors of ratings of importance in Ethnic Culture.

A second multiple linear regression was conducted to test the effect of Ethnicity, Athlete Type, and their interaction (Ethnicity X Athlete Type) on Sport Culture salience. The regression was found to be non-significant $[F(3,58)=1.782, p=.161]$ with an $R^{2}$ of .084 . Participants' predicted ratings of importance in Sport Culture was equal to $6.333-0.233$ (Ethnicity) - 0.733 (Athlete Type) + .318 (Ethnicity X Athlete Type). Athlete Type was coded as $0=\mathrm{NCAA}, 1=\mathrm{Club} /$ Intramural, and Ethnicity was coded as $0=$ Ethnic Majority, $1=$ Ethnic Minority groups. Ratings of importance in Sport Culture decreased by 0.233 for each Ethnicity group and 0.733 for each Athlete Type. Ethnic background, Athlete Type, and the interaction variable (Ethnic Background x Athlete Type) were not significant predictors of ratings of importance in Sport Culture. 
Appendix B: Table 1. Participant Demographic Characteristics

\begin{tabular}{|l|c|c|}
\hline \multicolumn{3}{|c|}{$n$} \\
\hline Gender & 38 & 61 \\
\hline Male & 24 & 38 \\
\hline Female & 23 & 37 \\
\hline Ethnicity & 8 & 12.9 \\
\hline European American / White & 10 & 16 \\
\hline African American / Black & 6 & 9 \\
\hline Hispanic / Latino & 2 & 3 \\
\hline Asian / Asian American & 13 & 20.9 \\
\hline Pacific Islander & \multicolumn{3}{|l}{} \\
\hline Other & 38 & 61 \\
\hline Athlete Type & 24 & 39 \\
\hline NCAA &
\end{tabular}

Note. $\mathrm{N}=62$ 
Appendix C: Table 2. Correlations of Variables in the Cultural Doman Menu (CDM) for Student Athletes

\begin{tabular}{lllllll}
\hline Variable & $\mathbf{1}$ & $\mathbf{2}$ & $\mathbf{3}$ & $\mathbf{4}$ & $\mathbf{5}$ & $\mathbf{6}$ \\
\hline \hline 1. Ethnic Culture & & & & & & \\
& - & & & & & \\
\end{tabular}

2. Religious/Spiritual

Culture $\quad \mathbf{0 . 5 0 4} * *$

3. Gender Identity/

Sexuality

$0.521 * * \quad 0.476 * *$

4. Academic Culture
$0.251 *$
$0.263^{*}$
$0.371 * *$

5. Work/ Employment

Culture

$0.322 * \quad \mathbf{0 . 4 9 2} * * \quad \mathbf{0 . 4 7 0} * * \quad \mathbf{0 . 5 7 2} * *$

6. Greek Culture

$\begin{array}{lllll}0.083 & 0.198 & \mathbf{0 . 2 7 6}^{* *} & 0.108 & 0.099\end{array}$

7. Sport Culture

$\begin{array}{llllll}0.050 & 0.137 & -0.150 & 0.172 & 0.266^{*} & \mathbf{- 0 . 5 3 1 * *}\end{array}$

Note. $N=62$, Bonferroni corrections were applied. $* p<0.05$ level (2 tailed), $* * p<0.01$ level (2 tailed) 
Appendix D: Figure 1. Median Ratings of Ethnic Culture Salience Parsed by Student Athlete Ethnicity

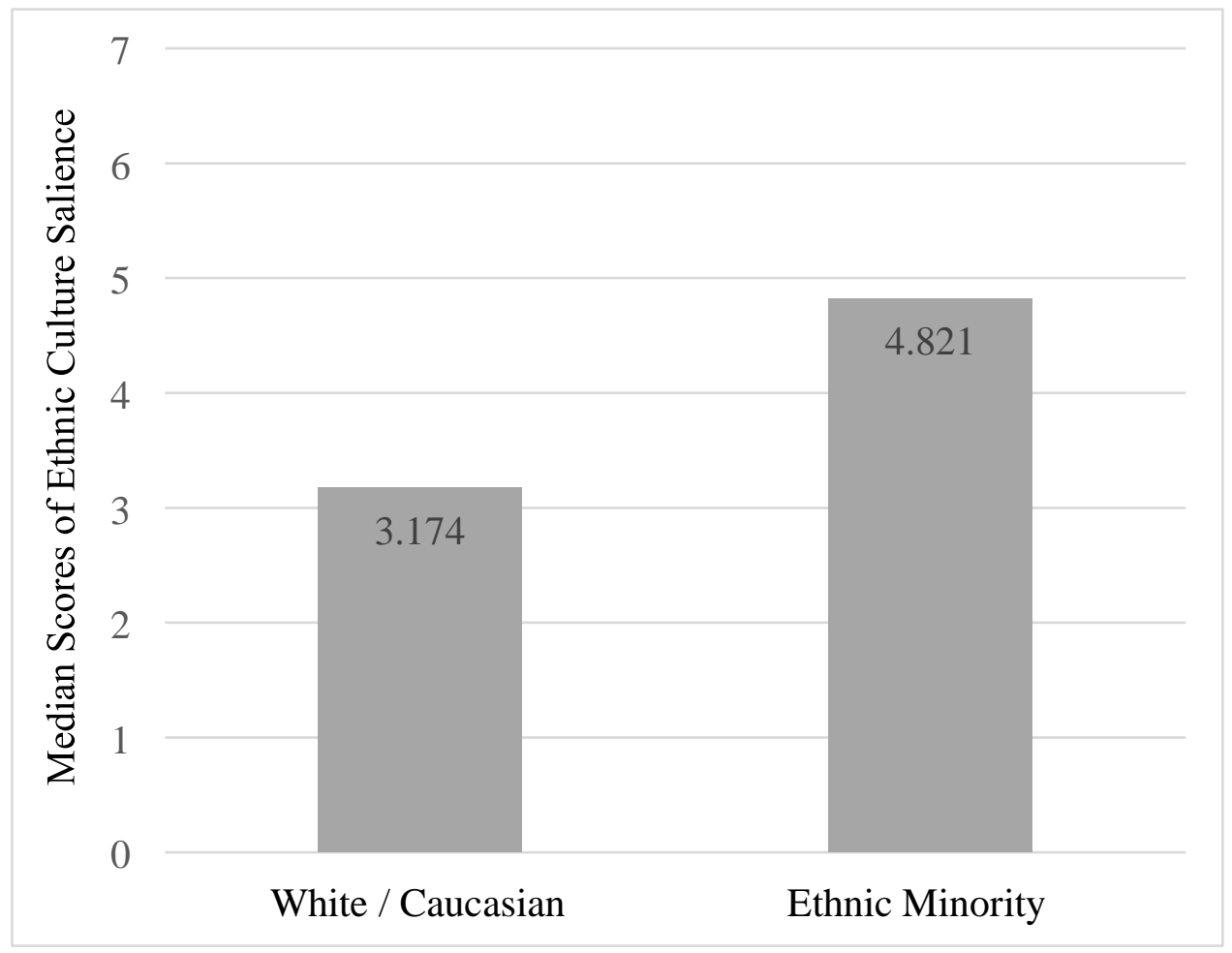

Note. There was a significant difference in ratings of importance of Ethnic Culture for Ethnic Majority athletes $(\mathrm{M}=3.174, \mathrm{SD}=1.403)$ and Ethnic Minority athletes $(\mathrm{M}=4.821, \mathrm{SD}=1.553), \mathrm{t}(60)=-4.1752, \mathrm{p}=.000$. 
Appendix E: Figure 2. Median Ratings of Ethnic Culture Salience Parsed by Student Athlete Type

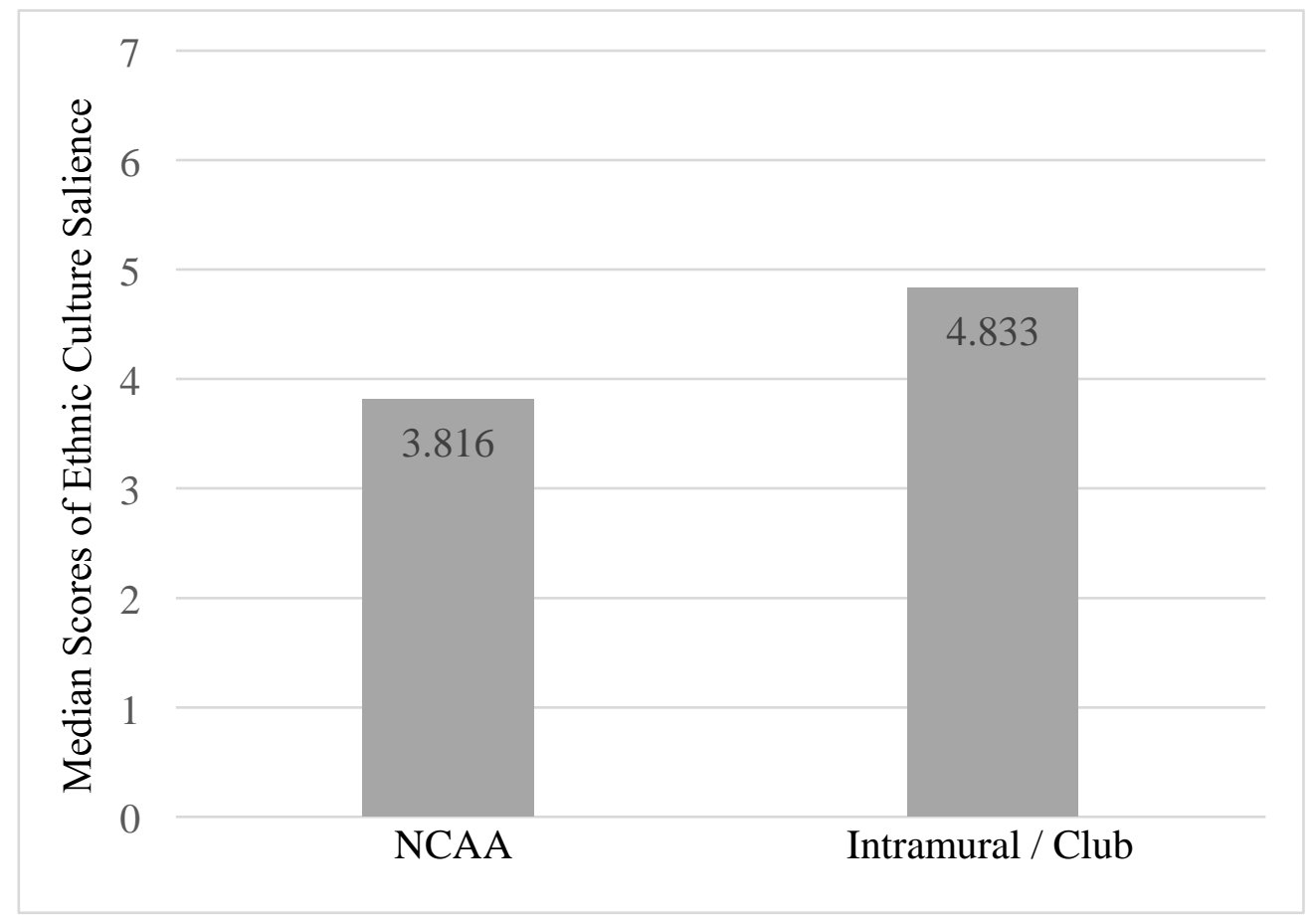

Note. There was a significant difference in ratings of importance in Ethnic Culture for NCAA $(M=3.816, S D=$ 1.738) and Club/Intramural athletes $(M=4.833, S D=1.434) ; t(60)=-2.397, p=.020$. 
Appendix F: Figure 3. Median Ratings of Sport Culture Salience Parsed by Student Athlete Type

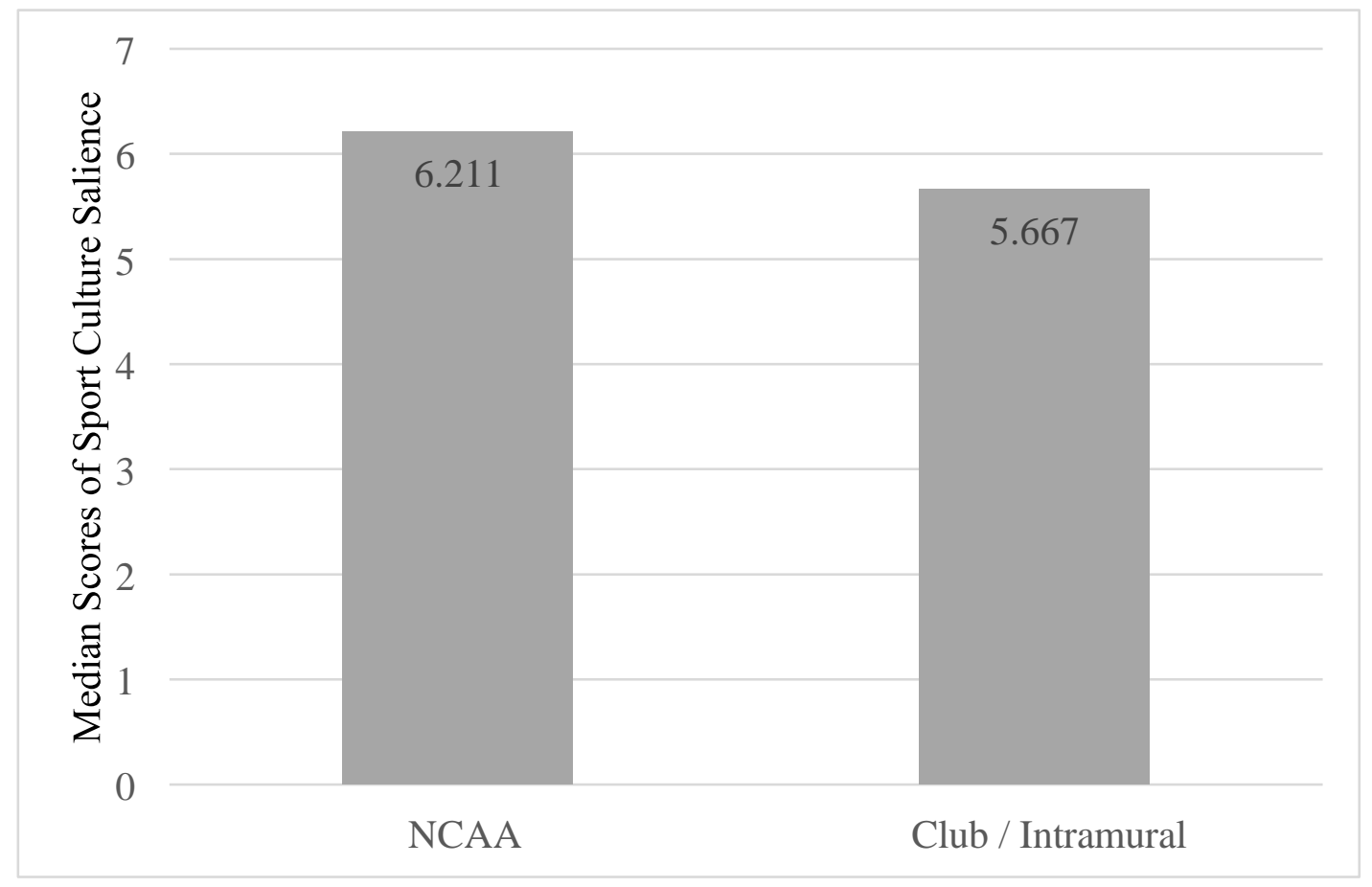

Note. There was a significant difference in ratings of importance in Sport Culture for NCAA $(M=6.211, S D=$ $.741)$ and Club/Intramural athletes $(M=5.667, S D=1.204), t(60)=2.206, p=.031$. 
Appendix G: Figure 4. Median Ratings of Sport Culture Salience Parsed by Student Athlete Ethnicity

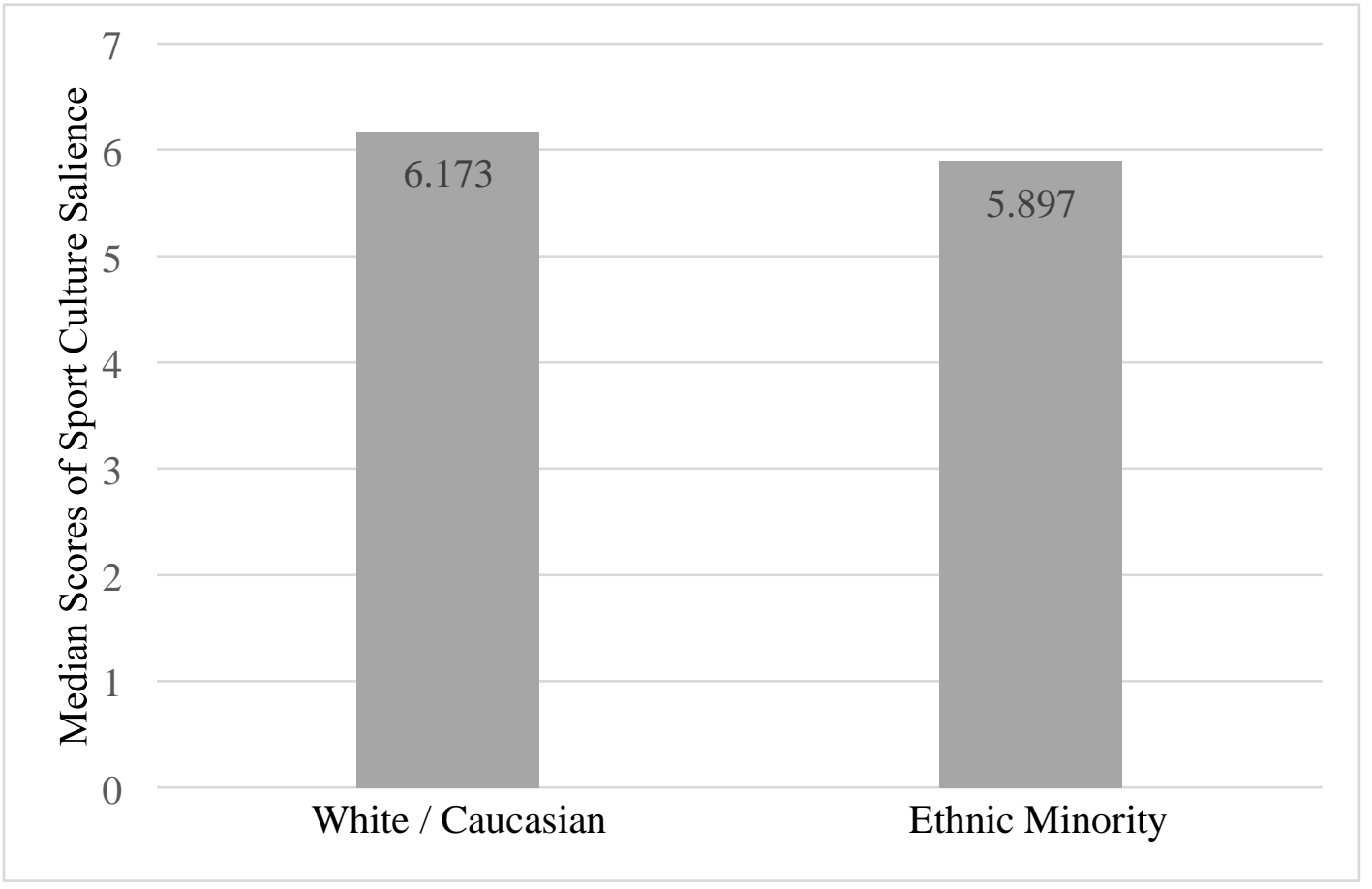

Note. There was not a significant difference in ratings of importance of Sport Culture for Ethnic Majority $(M=$ $6.173, S D=.834)$ and Ethnic Minority athletes $(M=5.897, S D=1.046), t(60)=1.080, p=.284$. 